\title{
Activity Screening of the Herb Caesalpinia sappan and an Analysis of Its Antitumor Effects
}

\author{
Yuan Li $\mathbb{D},{ }^{1}$ Minghong Dong $\mathbb{D}^{1},{ }^{1}$ Zijun Wu $\mathbb{D}^{2},{ }^{2}$ Yongqi Huang $\mathbb{D}^{1,3}$ Haibing Qian $\mathbb{D}^{1,3}$ \\ and Cong Huang $\mathbb{B D}^{1,3}$ \\ ${ }^{1}$ Guizhou University of Traditional Chinese Medicine, Guian District, Guiyang 550025, China \\ ${ }^{2}$ Tianjin University of Traditional Chinese Medicine, Jinghai District, Tianjin 301699, China \\ ${ }^{3}$ Guizhou Province Key Laboratory of Prescription and Syndrome Pharmacology in Chinese Medicine, Guian District, \\ Guiyang 550025, China
}

Correspondence should be addressed to Yongqi Huang; huangyongqi3319@163.com, Haibing Qian; qianhaibing337@gzy.edu.cn, and Cong Huang; huangcong236@163.com

Received 2 April 2021; Revised 17 May 2021; Accepted 18 June 2021; Published 28 June 2021

Academic Editor: Yu CAI

Copyright ( 2021 Yuan Li et al. This is an open access article distributed under the Creative Commons Attribution License, which permits unrestricted use, distribution, and reproduction in any medium, provided the original work is properly cited.

\begin{abstract}
Aim. Traditionally, C. sappan medicine was the heartwood, which needs to be cut down as a whole. In this research, the antitumor activity and mechanisms of the leaves and stems were compared with the roots of Caesalpinia sappan; it was in order to investigate whether stems and leaves of $C$. sappan could be used to replace heartwood for antitumor treatment, thereby reducing resource destruction. Methods. MTT assays were used to identify the active sites of C. sappan based on the application of human liver cancer (HuH-7) cells. High-performance liquid chromatography (HPLC) was used to analyze polar extracts. We also established a H22 hepatoma-bearing mouse model by administering intraperitoneal injections of petroleum ether extracts from the leaves and stems (SY(2) at doses of 20 and $65 \mathrm{mg} / \mathrm{kg}$. Mice in the i.g. group were administered intragastrically with the same extracts (at doses of 100 and $325 \mathrm{mg} / \mathrm{kg}$ ) at the same time (12 days). Results. The antitumor site of C. sappan was the petroleum ether extract. The IC 50 for the petroleum ether extract of roots (SG(2) was $56.10 \mu \mathrm{g} / \mathrm{ml}$, while that for the leaves and stems (SY(2) was $77.20 \mu \mathrm{g} / \mathrm{ml}$. Grey relational analysis indicated 11 active fraction peaks that were closely related to antitumor activity. The size of tumors in $\mathrm{H} 22$ hepatoma-bearing mice was reduced significantly in mice administered with petroleum ether extracts from the leaves and stems (inhibition rates of high doses were $55.31 \%$ and $60.56 \%$ ). Fibrous tissue proliferation, inflammatory cell infiltration, tumor cell necrosis, and the expression of proliferating cell nuclear antigen (PCNA) and vascular endothelial growth factor (VEGF) were all lower than in the control group (VEGF $P<0.001$ and PCNA $P<0.05$ ). Conclusion. Petroleum ether extracts of the roots, leaves, and stems of C. sappan exhibit certain antitumor effects. Our data indicate that the mechanisms underlying these effects may relate to a reduction in the expression of PCNA and VEGF and the inhibition of angiogenesis. Our findings indicate that we can expand the medicinal use of C. sappan to the leaves and stems, thus improving resource utilization and reducing resource damage.
\end{abstract}

\section{Introduction}

As a common Hmong medicine, Caesalpinia sappan is the dried heartwood of a legume used in Guizhou folk herbal medicine for the treatment of tumors. The roots and bark of C. sappan were listed as sources for a herbal drug in the 2019 edition of Quality Standards for Chinese Medicinal Materials and Ethnic Medicinal Materials in Guizhou Province. The main ingredients of C. sappan are flavonoids, diterpenes, lactones, coumarins, and amides. Recent research on
C. sappan found that a crude water extract of C. sappan can inhibit a variety of cancer cells or induce their apoptosis [1-3], thus demonstrating the value of further development and utilization. Other research showed that an ethyl acetate extract of C. sappan had a significant inhibitory effect on the growth of HGC-27 cells [4]. Protosappanin B has been shown to exert an inhibitory effect on the proliferation of BTT, T24, HeLa, and SW480 tumor cells [5]. In addition, brazilin has been shown to significantly inhibit the growth and proliferation of human bladder T24 cancer cells; the 
mechanism involved may be related to the upregulation of C-Fos expression [6]. Brazilin not only inhibits the proliferation of skin cancer cells (A431, BCC, SCC25, and A375) but also can also promote apoptosis in skin cancer cells by activating the expression of caspase-3 [7]. A previous study of the effect of brazilin on the inhibition of growth and the induction of apoptosis in human glioblastoma U87 cells showed that brazilin promotes cell apoptosis by increasing the cleavage of PARA and by downregulating the expression levels of caspase-3 and caspase-7 [8]. In another study, investigating the invasion of mouse liver cancer $\mathrm{H} 22$ cells, both protosappanin $\mathrm{B}$ and mitomycin were found to increase the survival time of Kunming mice [9]. Brazilin was also shown to exhibit a potential inhibitory effect on the tumorigenicity of mouse lung cancer A549-FIG cells in $\mathrm{BALB} / \mathrm{c}$ nude mice by inhibiting the phosphorylation of barrier-to-autointegration factor (BAF) [10].

Traditionally, the roots and trunks of $C$. sappan are used to make medicinal extracts. However, this practice causes irreversible damage to the trees and severe damage to the resource itself. There are no reports in the existing literature that compare extracts made from the roots of $C$. sappan with those made from the leaves and stems with regard to anticancer effects. In the present study, we compared the efficacy of petroleum ether extract prepared from the roots with leaves and stems of $C$. sappan to inhibit the growth of human liver cancer (HuH-7) cells and as an antitumor therapy for $\mathrm{H} 22$ tumor-bearing mice. In this paper, we provide experimental evidence that supports the preparation of medicinal extracts from the stems and leaves of C. sappan, thus expanding the way this resource is used and providing options to prevent damage from being incurred by these valuable trees.

\section{Materials and Methods}

2.1. Drugs and Reagents. Antibodies(PCNA (clone VG1) and VEGF (clone VG1)) were purchased from DAKO Company. Trypsin (batch no. SH30042.01), DMEM (batch no. NXKO731), and FBS (batch no. NXCO582) were purchased from HyClone. Fluorouracil was acquired from Tianjin Jinyao while acetonitrile (no. 20121018), methanol (batch no. 20120201), dimethyl sulfoxide (DMSO, batch no. 2012062), and phosphoric acid were purchased from Tianjin Kemiou Company. Epirubicin was provided by the Beijing Botai Company. Paraformaldehyde tissue fixation solution was provided by the Second Affiliated Hospital of Guizhou University of Traditional Chinese Medicine.

2.2. Plant Material. Caesalpinia sappan (L.) Tod. plants were gathered from Ceheng County in Guizhou Province, China. The voucher specimen for C. sappan is GZTM 0018426 and is maintained in Guizhou University of Traditional Chinese Medicine, Guiyang.

First, we ground $1.0 \mathrm{~kg}$ of dry leaves and stems from C. sappan into a powder and then refluxed three times $(75 \%$ ethanol, $5000 \mathrm{ml} ; 4$ hours per reflux). The extracts were then mixed and concentrated; the ethanol extract yielded $143.0 \mathrm{~g}$ (SY (1). The dregs were then dried and extracted with water three times. Next, we carried out six refluxes lasting 0.5 hours, 8 refluxes lasting 1 hour, and 12 refluxes lasting 2 hours. The solvent was then recovered so that we were left with the water extract; the yield of the water extract was $37.1 \mathrm{~g}$ (SY6)). Different polar extracts were extracted from the ethanol extract, yielding $6.29 \mathrm{~g}$ of hydromethanolic extract (SY(5)), $3.15 \mathrm{~g}$ of n-butanol extract (SY(4)), $2.02 \mathrm{~g}$ of ethyl acetate extract (SY(3)), and $1.38 \mathrm{~g}$ of petroleum ether extract (SY(2)).

This procedure was then repeated to prepare extracts from the roots of C. sappan (1.0 kg). Using this strategy, we obtained $112.5 \mathrm{~g}$ of ethanol extract (SG(1)), $0.05 \mathrm{~g}$ of petroleum ether extract (SG(2)), $5.72 \mathrm{~g}$ of ethyl acetate extract (SG(3), $1.12 \mathrm{~g}$ of $\mathrm{n}$-butanol extract (SG(4)), $1.05 \mathrm{~g}$ of hydromethanolic extract (SG(5)), and $19.6 \mathrm{~g}$ of water extract (SG6).

2.3. Cell Lines. The $\mathrm{H} 22$ mouse liver cancer cell line and the human liver cancer HuH-7 cell line were purchased from the Shanghai Institute of Cell Research, Chinese Academy of Sciences. Dulbecco's Modified Eagle Medium (DMEM) was used to preserve cells (the medium contained penicillin $G$ (100 U/ml), FBS, streptomycin $(100 \mathrm{U} / \mathrm{ml})$, and L-glutamine $(2 \mathrm{mM}) \mathrm{mg} / \mathrm{ml})$.

2.4. Animals. Our experiments involved male and female Kunming mice (certificate no. SCXU (Qian) 2015-0004, weighing 18-22 g). The Local Committee on Animal Care and Use approved the experimental procedures. All experimentation was conducted according to guidelines provided by the Committee for Ethics in Animal Research (CEPA). Mice were housed under standard conditions in a breeding room (12 h dark/light cycle; $20-25^{\circ} \mathrm{C} ; 60-75 \%$ humidity) with ad libitum access to food and water.

2.5. Determining the Effects of C. sappan Extracts on the Inhibition of Human Liver Cancer HuH-7 Cell Proliferation. The effects of C. sappan extracts were determined by MTT assays and by determining the $\mathrm{IC}_{50}$ of growth inhibition.

2.5.1. MTT Assays. These assays were carried out as described previously $[11,12]$. First, a cell suspension $\left(1 \times 10^{5}\right.$ cells $\left./ \mathrm{ml}\right)$ was added to a 96 -well plate. Then, $100 \mu \mathrm{l}$ of each extract was placed in separate wells and placed in an incubator $\left(5 \% \mathrm{CO}_{2}, 37^{\circ} \mathrm{C}\right)$ for $24 \mathrm{~h}$. Water extracts and hydromethanolic extracts were dissolved with NS. DMSO $(<0.1 \%)$ was used to aid the solubilization of n-butanol, ethyl acetate, and petroleum ether extracts. Administration groups were incubated with medicated serum (at doses of $100 \mu \mathrm{g} / \mathrm{ml}, 20 \mu \mathrm{g} / \mathrm{ml}$, and $4 \mu \mathrm{g} / \mathrm{ml}$ ); three replicates were set up for each group. After $48 \mathrm{~h}$ of incubation, $50 \mu \mathrm{l}$ of MTT $(5 \mathrm{mg} / \mathrm{ml})$ was added to each well; this was followed by a $4 \mathrm{~h}$ incubation period. Next, the medium was removed and DMSO $(150 \mu \mathrm{l})$ was added to each well. Absorbance was then tested by a Multiskan FC Microplate Reader (Thermo Fisher Scientific) at $570 \mathrm{~nm}$. These experiments were repeated twice. Data were then used to calculate the cell proliferation inhibition rate $\left(\mathrm{IR}_{1}\right)$, as shown in the following equation: 


$$
\mathrm{IR}_{1}=\left[\frac{(\mathrm{OD} \text { value of control group }- \text { OD value of experimental group })}{\text { OD value of control group }}\right] \times 100 \% .
$$

2.5.2. Determining the Antitumor Effects of Active Fractions. Based on preliminary experiments, the most effective active fractions were the petroleum ether extracts. Using equation (1), we determined the inhibition rate $\left(\mathrm{IR}_{1}\right)$ of $\mathrm{HuH}-7$ cells. Experimental groups featured a zero group (no cells), positive control groups (containing epirubicin at final concentrations of $20,10,5,2.5$, and $1.25 \mu \mathrm{g} / \mathrm{ml}$ ), two fraction administration groups (at doses of 200,100,50,25, and $12.5 \mu \mathrm{g} / \mathrm{ml}$ ), and two control groups (PBS or DMSO).

2.6. High-Performance Liquid Chromatography (HPLC) Analysis. HPLC was used to investigate the stability, repeatability, and precision of all extracts. The RSD was less than $3.0 \%$.

2.6.1. Sample Solution Preparation. Samples of each polar extract $(0.2 \mathrm{~g})$ were weighed accurately and placed in different volumetric flasks $(10 \mathrm{ml})$. A certain volume of methanol was then added into the volumetric flasks which were then shaken thoroughly. The samples were then sonicated for $30 \mathrm{mins}$ and cooled at $20^{\circ} \mathrm{C}$. The solutions were then filtered with a $0.45 \mu \mathrm{m}$ microporous membrane and used as test samples.

2.6.2. Chromatographic Conditions. Extracts were analyzed by HPLC (Agilent 1100 with a quaternary pump and degasser, USA) in isocratic mode. All analyses were performed maintained at $25^{\circ} \mathrm{C}$ on an analytical Dima column $(250 \mathrm{~mm} \times 4.6 \mathrm{~mm}, 5 \mu \mathrm{m})$. The injection volume and flow rate were $10 \mu \mathrm{l}$ and $1.0 \mathrm{ml} / \mathrm{min}$, respectively. Gradient elution was performed with mobile phases $\mathrm{A}(0.1 \%$ phosphoric acid), $\mathrm{B}$ (methanol), and $\mathrm{C}$ (acetonitrile) as follows: $0 \mathrm{~min}$, $5 \% \mathrm{~B}$ and $5 \% \mathrm{C} ; 1 \mathrm{~min}, 15 \% \mathrm{~B}$ and $15 \% \mathrm{C} ; 60 \mathrm{~min}, 25 \% \mathrm{~B}$ and $25 \% \mathrm{C} ; 140 \mathrm{~min}, 33 \% \mathrm{~B}$ and $33 \% \mathrm{C} ; 270 \mathrm{~min}, 40 \% \mathrm{~B}$ and $40 \%$
C; $340 \mathrm{~min}, 45 \% \mathrm{~B}$ and $45 \% \mathrm{C}$; and $360 \mathrm{~min}, 50 \% \mathrm{~B}$ and $50 \%$ C. The detection wavelength was $240 \mathrm{~nm}$.

2.7. The Mouse Tumor Model. H22 hepatoma-bearing mice were divided randomly into an intragastric (i.g.) low-dose group and high-dose group, a fluorouracil (FU) group, a control group, a low-dose group, and a high-dose group. On the basis of acute toxicity experiments, the SY(2) $L_{50}$ was $1961 \mathrm{mg} / \mathrm{kg}$. The dose administered in the high-dose group (i.p.) was $1 / 30$ of the $\mathrm{LD}_{50}$, the low-dose (i.p.) was $1 / 3$ of the high dose. The dose administered to the high-dose group (i.g.) was $1 / 6$ of the $\mathrm{LD}_{50}$ while the low-dose (i.g.) was $1 / 3$ of the high-dose. At the end of the 12-day administration period, we measured pathological changes and measured the tumor weight. We also evaluated the expression of VEGF and PCNA in tumor tissues.

2.7.1. Administration, Grouping, and Modeling. Ascites tumor-derived mice were produced by implanting $\mathrm{H} 22$ mouse hepatoma cells $(0.2 \mathrm{ml} /$ mouse $)$ into the abdominal cavity. After 7 days, we used an injector to extract the nonbloody ascites which were then placed into an aseptic Petri dish [13]. Cells from the ascites were diluted to $1.0 \times 10^{7}$ cells $/ \mathrm{ml}$. Then, $0.2 \mathrm{ml}$ of ascites was inoculated into the left anterior axillary of each mouse $\left(2.0 \times 10^{6}\right.$ tumor cells per mouse).

In total, 60 mice were grouped as follows $(n=10$ per group): i.g. low-dose group $(100 \mathrm{mg} / \mathrm{kg})$, i.g. high-dose group ( $325 \mathrm{mg} / \mathrm{kg})$, FU group ( $83 \mathrm{mg} / \mathrm{kg})$, control group, i.p. low-dose group $(20 \mathrm{mg} / \mathrm{kg})$, and i.p. high-dose group $(65 \mathrm{mg} / \mathrm{kg})$. SY(2) was administered to each mouse from the third day after vaccination (at a dose of $0.2 \mathrm{ml} / 10 \mathrm{~g}$ ). All mice were euthanized on day 13 . The tumor inhibition rate $\left(\mathrm{IR}_{2}\right)$ was then determined by weighing the tumors and applying the following equation:

$$
\mathrm{IR}_{2}=\left\{\frac{[\text { weight of tumors (control group) }- \text { weight of tumors (dosing group) }]}{\text { weight of tumors (control group) }}\right\} \times 100 \%
$$

2.7.2. Pathological Analysis of Tumor Tissue. Tumor tissue was fixed, dehydrated, embedded, sectioned, and then stained with hematoxylin-eosin (HE). A light microscope was then used to determine whether any pathological changes had occurred. Lesions were then assessed using a scoring system ( 3 points: lesions occupy $>50 \%$; 2 points: lesions occupy $30-50 \%$; 1 point: lesions occupy $<30 \%)$ used to assess pathological changes. We also evaluated a range of indicators, including fibrous tissue proliferation, inflammatory cell infiltration, and tumor cell necrosis.
2.7.3. Assays to Determine the Expression of VEGF and $P C N A$. Immunohistochemistry was carried out in accordance with the manufacturer's instructions using the following groupings: intragastric (i.g.), low-dose group, i.g. high-dose group, fluorouracil (FU) group, control group, intraperitoneal injection (i.p.) high-dose group, and i.p. lowdose group.

Mice were sacrificed after 13 days of administration. The tumor tissues were then soaked, dehydrated, embedded, deparaffinized, and sectioned at $4 \mu \mathrm{m}$. The sections were then 
incubated with VEGF, washed with PBS, soaked in $0.3 \%$ $\mathrm{H}_{2} \mathrm{O}_{2}$ buffer (30 min), washed, incubated in PBS (10 min), and then incubated with primary antibody for $20 \mathrm{~min}$ at $4{ }^{\circ} \mathrm{C}$. Sections were then washed with PBS $(10 \mathrm{~min})$, incubated with EnVision $^{\mathrm{TM}}$ for 20 min, and then incubated with a color source substrate solution incubated for $20 \mathrm{~min}$. Immunopositivity was indicated as brown/yellow particles located in the cytoplasm. Five dense areas of tissues (100 fields) of neovascularization were selected [14] and the number of microvessels in each view field-of-view (200 fields) were counted.

Other portions of the tissue were immunohistochemically stained for PCNA. PCNA-positive protein (brown/ yellow particles) were located in the nucleus. Five tissue areas were selected at random to count PCNA-positive tumor cells (400 fields).

2.8. Statistical Methods. Data were analyzed with SPSS version 23.0. $P$ values of 0.05 or less were considered to be statistically significant. Data are presented as mean\pm standard deviation (SD) for individual groups $(n \geq 3)$.

\section{Results}

3.1. C. sappan Extracts Inhibited the Proliferation of $\mathrm{HuH}-7$ Cells. The antitumor results for C. sappan extracts are summarized in Table 1. Analysis showed that SY(2) and SG(2) significantly inhibited the proliferation of $\mathrm{HuH}-7$ cells (Figures 1-3). These data indicated that C. sappan petroleum ether extracts (SY(2) and SG(2)) might be the most effective active fractions against tumors. The mean of the $\mathrm{IC}_{50}$ values for the duplicated experiments was taken as the final index for inhibition. The $\mathrm{IC}_{50}$ value of epirubicin, SY(2), and SG(2), were $5.11 \mu \mathrm{g} / \mathrm{ml}, 77.20 \mu \mathrm{g} / \mathrm{ml}$, and $56.10 \mu \mathrm{g} / \mathrm{ml}$ (Table 2). The $\mathrm{IC}_{50}$ of SG(2) was smaller than that of SY(2). Furthermore, the inhibitory effect of SY(2) was stronger than SG(2).

3.2. HPLC Analysis. Figure 3 shows an HPLC chromatogram of the polar extracts prepared from C. sappan roots. Compared with SG(2), between $100 \mathrm{~min}$ and $410 \mathrm{~min}, \mathrm{SG}(4)$, SG(5), and SG(6) showed no chromatographic peaks. From $0 \mathrm{~min}$ to $130 \mathrm{~min}$, SG(3) had the most chromatographic peaks. This data implies that the roots had more components than the stems and leaves. The chromatogram of SY(2) was significantly different from the other four samples (Figure 4). When compared with SY(3), SY(4), SY(5), and SY(6), SY(2) showed no common peaks.

HPLC analysis found that 15906.1 and 13736.9 were the total peak areas for the active fractions (SG(2) and SY(2)). There were 26 common peaks (Figures 5-9).

3.3. Grey Relational Analysis. Analysis showed that the most effective active fractions were the petroleum ether extracts of C. sappan (SY(2) and SG(2)). The $\mathrm{IC}_{50}$ for $\mathrm{HuH}-7$ cells was used as the pharmacodynamic index for active chemicals. We then used Grey correlation to analyze the association between antitumor activity and common peaks [15-17].
Analysis showed that the common peaks were correlated to antitumor activity (correlation coefficients $>0.6$ ): $31>3>33>5>29>35>6>30>15>28>26 \quad$ peaks (Table 3).

3.4. Analysis of Tumor Weight. Table 4 and Figure 10(a) show that tumor weight in the FU group was significantly reduced compared with the control group $(P<0.001)$; the high-dose i.p. group $(P<0.001)$ and i.g. group $(P<0.05)$ showed similar effects. This suggested that a high dose (i.g. and i.p.) could inhibit tumor growth. However, the weight of tumors in the low-dose groups (i.g. and i.p.) were not significantly different from the control group.

3.5. Pathological Scores of Tumors (HE Staining). In the control group, tumor cells showed deep chromatin staining, irregular shapes, and polymorphism (Figures 10(b) and 11). In the treatment groups, tumor cells showed differing extents of necrosis, fibrous tissue proliferation, and the infiltration of inflammatory cells. In the low-dose groups, there was no significant effect on pathological changes related to tumors. In the high-dose groups, there was a significant reduction in the lesion score $(P<0.05)$ (Table $5(\mathrm{a}))$.

3.6. VEGF Expression. Light microscopy showed that VEGFpositive products were localized in the cytoplasm and expressed in the cytoplasm of the arterial endothelial cells, small veins, and capillaries in tumors (Figures 10(c) and 11). Angiogenesis in tumor tissue was significantly inhibited in the low-dose, high-doses, and FU injection groups $(P<0.001)$ (Table $5(\mathrm{~b}))$.

3.7. PCNA Expression. Light microscopy detected PCNApositive products in the nuclei (Figures 10(d) and 11). The expression of PCNA in the high-dose groups was significantly lower $(P<0.05)$ than in the control group (Table 5 (c)). Tumor cell proliferation was significantly inhibited in the i.p. and i.g. high-dose and FU injection groups.

\section{Discussion}

In this study, HPLC chromatograms demonstrated that there were similar chemical components in the roots, stems, and leaves. We also used the Grey relational analysis to evaluate the relative contribution of each component to tumor suppression; 11 common peaks were shown to be correlated with tumor inhibition activity. These components exhibited a congenerous antitumor effect that was consistent with the advantages of traditional Chinese medicine (multicomponents and multitargets) [18]. Analysis showed that a C. sappan represented a key resource for a large number of antitumor compounds, thus providing a useful foundation for future research focusing on identifying compounds with antitumor activity.

Tables 1 and 2 show that the petroleum ether extract of C. sappan exhibited the best antitumor activity. The petroleum ether extract of leaves and stems (SY2) 
TABLE 1: The inhibitory effect of C. sappan extracts $(n=6$, mean \pm SD).

\begin{tabular}{|c|c|c|c|c|c|c|c|}
\hline Group & Dose $(\mu \mathrm{g} / \mathrm{ml})$ & OD value & $\mathrm{IR}_{1}(\%)$ & Group & Dose $(\mu \mathrm{g} / \mathrm{ml})$ & OD value & $\mathrm{IR}_{1}(\%)$ \\
\hline NS & - & $0.2353 \pm 0.1087$ & 0 & NS & - & $0.2307 \pm 0.1079$ & 0 \\
\hline DMSO & - & $0.2018 \pm 0.0572$ & 0 & DMSO & - & $0.1963 \pm 0.0530$ & 0 \\
\hline \multirow{3}{*}{ SY(2) } & 100 & $0.0900 \pm 0.0466^{*}$ & 55.4 & \multirow{3}{*}{ SG(2) } & 100 & $0.0830 \pm 0.0656^{*}$ & 57.7 \\
\hline & 20 & $0.1412 \pm 0.0468$ & 30.0 & & 20 & $0.1206 \pm 0.0284^{*}$ & 38.6 \\
\hline & 4 & $0.1983 \pm 0.0613$ & 1.7 & & 4 & $0.1880 \pm 0.0366$ & 4.2 \\
\hline \multirow{3}{*}{ SY(3) } & 100 & $0.2028 \pm 0.0610$ & 0 & \multirow{3}{*}{ SG(3) } & 100 & $0.1912 \pm 0.0548$ & 2.6 \\
\hline & 20 & $0.1938 \pm 0.0536$ & 4.0 & & 20 & $0.1918 \pm 0.0579$ & 2.3 \\
\hline & 4 & $0.2037 \pm 0.0803$ & 0 & & 4 & $0.2148 \pm 0.0531$ & 0 \\
\hline \multirow{3}{*}{ SY(4) } & 100 & $0.2035 \pm 0.0600$ & 0 & \multirow{3}{*}{ SG(4) } & 100 & $0.1920 \pm 0.0515$ & 2.2 \\
\hline & 20 & $0.2083 \pm 0.0661$ & 0 & & 20 & $0.2142 \pm 0.0578$ & 0 \\
\hline & 4 & $0.2090 \pm 0.0817$ & 0 & & 4 & $0.1883 \pm 0.0564$ & 4.1 \\
\hline \multirow{3}{*}{ SY(5) } & 100 & $0.2222 \pm 0.0975$ & 5.6 & \multirow{3}{*}{ SG(5) } & 100 & $0.2248 \pm 0.0959$ & 2.6 \\
\hline & 20 & $0.2193 \pm 0.0844$ & 6.8 & & 20 & $0.2225 \pm 0.0892$ & 3.6 \\
\hline & 4 & $0.2253 \pm 0.0835$ & 4.2 & & 4 & $0.2215 \pm 0.0866$ & 4.0 \\
\hline \multirow{3}{*}{ SY(6) } & 100 & $0.2177 \pm 0.0971$ & 7.5 & \multirow{3}{*}{ SG@6 } & 100 & $0.2257 \pm 0.0917$ & 2.2 \\
\hline & 20 & $0.2270 \pm 0.0989$ & 3.5 & & 20 & $0.2287 \pm 0.0990$ & 0.9 \\
\hline & 4 & $0.2387 \pm 0.1039$ & 0 & & 4 & $0.2210 \pm 0.0825$ & 4.2 \\
\hline
\end{tabular}

Note: compared with the DMSO control group, ${ }^{*} P<0.05$.

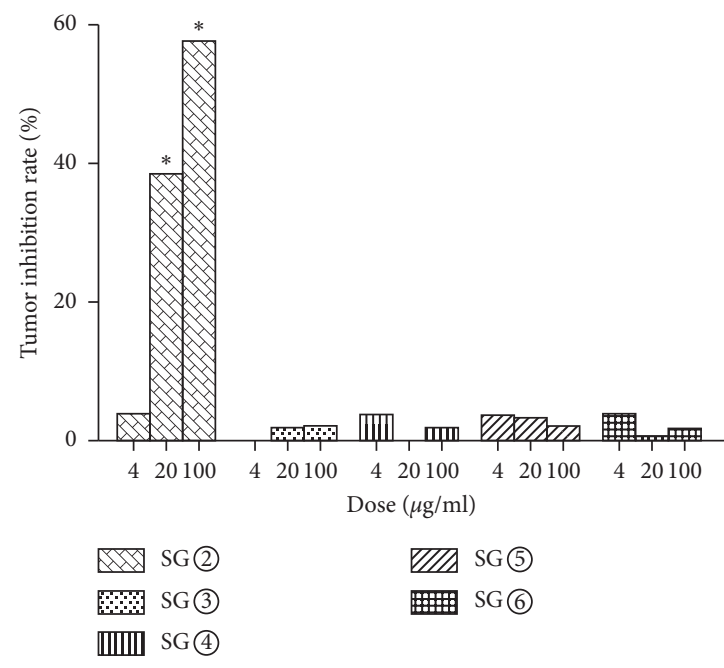

(a)

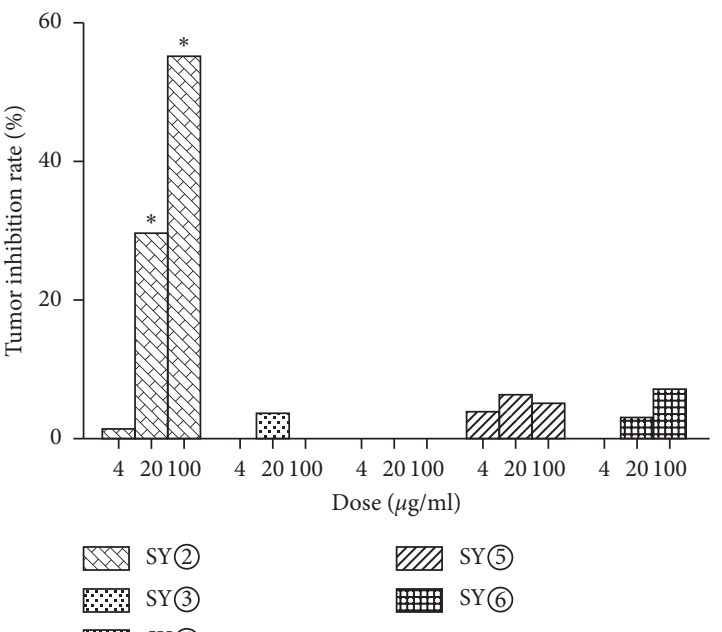

(b)

Figure 1: The inhibitory effect of C. sappan extracts. (a) The roots of C. sappan. (b) The leaves and stems of C. sappan. Compared with the DMSO control group, ${ }^{*} P<0.05$.

significantly inhibited the proliferation of tumor cells with an $\mathrm{IC}_{50}$ of $77.20 \mu \mathrm{g} / \mathrm{ml}$; this was even better than the roots, the resource that is traditionally used to prepare extracts (roots: SG(2); $\mathrm{IC}_{50}=56.10 \mu \mathrm{g} / \mathrm{ml}$ ). Therefore, it follows that leaves and stems could also be used as a medicine for antitumor therapy. The Grey relational analysis indicated that 11 active fractions exhibited common peaks (31\#, 3\#, $33 \#, 5 \#, 29 \#, 35 \#, 6 \#, 30 \#, 15 \#, 28 \#$, and 26\#) that were closely related to antitumor activity. This foundation was used in the next step of our research which focused on extracting, isolating, and identifying compounds with antitumor activity.

There was a significant reduction in the tumor tissue of $\mathrm{H} 22$ hepatoma-bearing mice in response to high-dose administration (Table 4). Tumor cells in the control group showed deep chromatin staining, irregular shapes, and polymorphism (Figures 10(b) and 11). In the treatment groups, the tumor cells exhibited differing degrees of necrosis, fibrous tissue proliferation, and the infiltration of inflammatory cells. The lesion score for tumor cells in the high-dose groups was significantly lower than in the other groups, thus showing that the petroleum ether extract of leaves and stems had a reliable and precise antitumor effect in vivo. Compared to other groups, the high-dose treatment groups showed reduced fibrous tissue proliferation, inflammatory cell infiltration, and necrosis in tumor cells; these groups also showed reduced expression of PCNA and VEGF. 


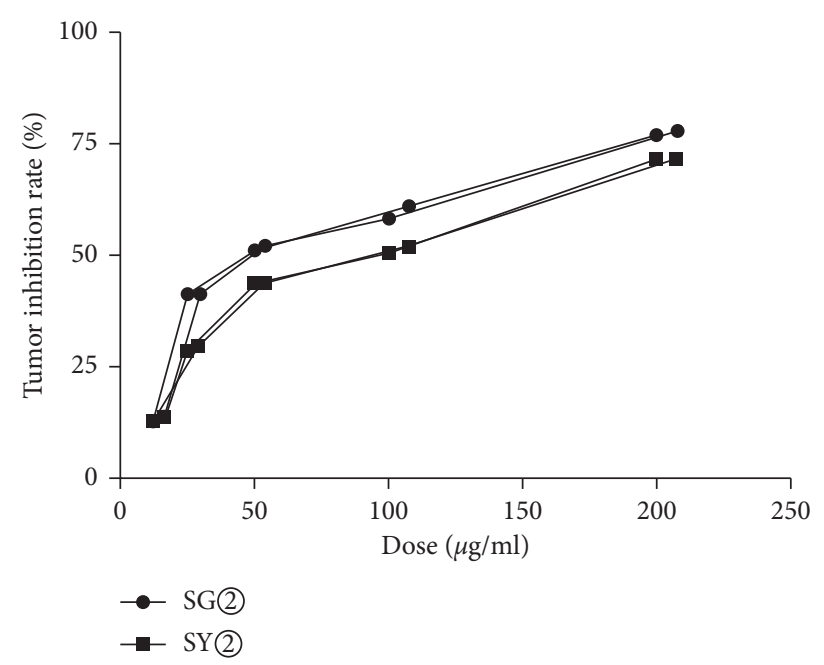

Figure 2: Inhibition curves for SY(2) and SG(2).
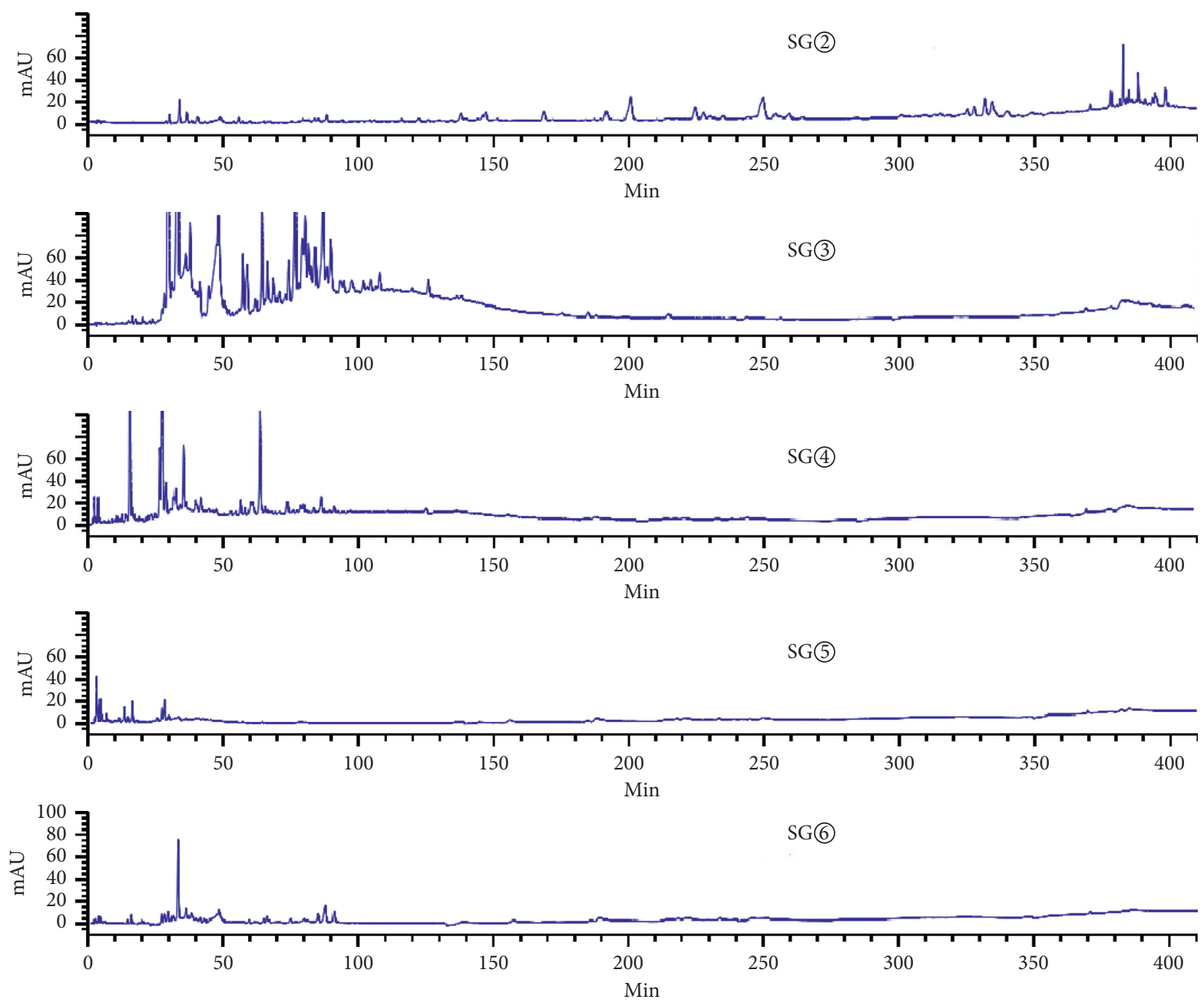

FIGURE 3: HPLC chromatograms for water extract (SG(6), hydromethanolic extract (SG(5), n-butanol extract (SG(4)), ethyl acetate extract (SG(3), and petroleum ether extract (SG(2), prepared from the roots of C. sappan. 
TABLE 2: The inhibitory effect of SY(2) and SG(2) $(n=3$, mean \pm SD).

\begin{tabular}{|c|c|c|c|c|c|c|c|}
\hline \multirow{2}{*}{ Group } & \multirow{2}{*}{ Dose $(\mu \mathrm{g} / \mathrm{ml})$} & \multicolumn{3}{|c|}{ First experiment } & \multicolumn{3}{|c|}{ Second experiment } \\
\hline & & OD value & $\mathrm{IR}_{1}(\%)$ & $\mathrm{IC}_{50}(\mu \mathrm{g} / \mathrm{ml})$ & OD value & $\mathrm{IR}_{1}(\%)$ & $\mathrm{IC}_{50}(\mu \mathrm{g} / \mathrm{ml})$ \\
\hline PBS & - & $0.1838 \pm 0.0082$ & 0 & - & $0.1860 \pm 0.0068$ & 0 & - \\
\hline DMSO & - & $0.1752 \pm 0.0028$ & 0 & - & $0.1790 \pm 0.0104$ & 0 & - \\
\hline \multirow{5}{*}{ SY(2) } & 200 & $0.0500 \pm 0.0164$ & 71.5 & \multirow{5}{*}{76.6} & $0.0523 \pm 0,0169$ & 71.6 & \multirow{5}{*}{77.8} \\
\hline & 100 & $0.0843 \pm 0.0460$ & 51.9 & & $0.0912 \pm 0.0470$ & 50.5 & \\
\hline & 50 & $0.0990 \pm 0.0380$ & 43.5 & & $0.1007 \pm 0.0437$ & 43.6 & \\
\hline & 25 & $0.1247 \pm 0.0190$ & 28.9 & & $0.1300 \pm 0.0251$ & 29.5 & \\
\hline & 12.5 & $0.1510 \pm 0.0318$ & 13.9 & & $0.1607 \pm 0.0267$ & 12.8 & \\
\hline \multirow{5}{*}{ SG(2) } & 200 & $0.0390 \pm 0.0204$ & 77.7 & \multirow{5}{*}{56.05} & $0.0413 \pm 0.0212$ & 76.9 & \multirow{5}{*}{56.14} \\
\hline & 100 & $0.0733 \pm 0.0458$ & 58.2 & & $0.0700 \pm 0.0396$ & 60.9 & \\
\hline & 50 & $0.0841 \pm 0.0338$ & 52.0 & & $0.0877 \pm 0.0360$ & 51.0 & \\
\hline & 25 & $0.1027 \pm 0.0317$ & 41.4 & & $0.1053 \pm 0.0291$ & 41.2 & \\
\hline & 12.5 & $0.1520 \pm 0.0211$ & 13.2 & & $0.1560 \pm 0.0250$ & 12.8 & \\
\hline \multirow{5}{*}{ Epirubicin } & 20 & $0.0289 \pm 0.0112$ & 83.5 & \multirow{5}{*}{5.42} & $0.0273 \pm 0.0103$ & 84.7 & \multirow{5}{*}{4.79} \\
\hline & 10 & $0.0667 \pm 0.0103$ & 61.9 & & $0.0657 \pm 0.0104$ & 63.3 & \\
\hline & 5 & $0.0898 \pm 0.0189$ & 48.7 & & $0.0839 \pm 0.0183$ & 53.1 & \\
\hline & 2.5 & $0.1135 \pm 0.0121$ & 35.2 & & $0.1102 \pm 0.0118$ & 38.5 & \\
\hline & 1.25 & $0.1563 \pm 0.0134$ & 10.7 & & $0.1545 \pm 0.0133$ & 13.6 & \\
\hline
\end{tabular}
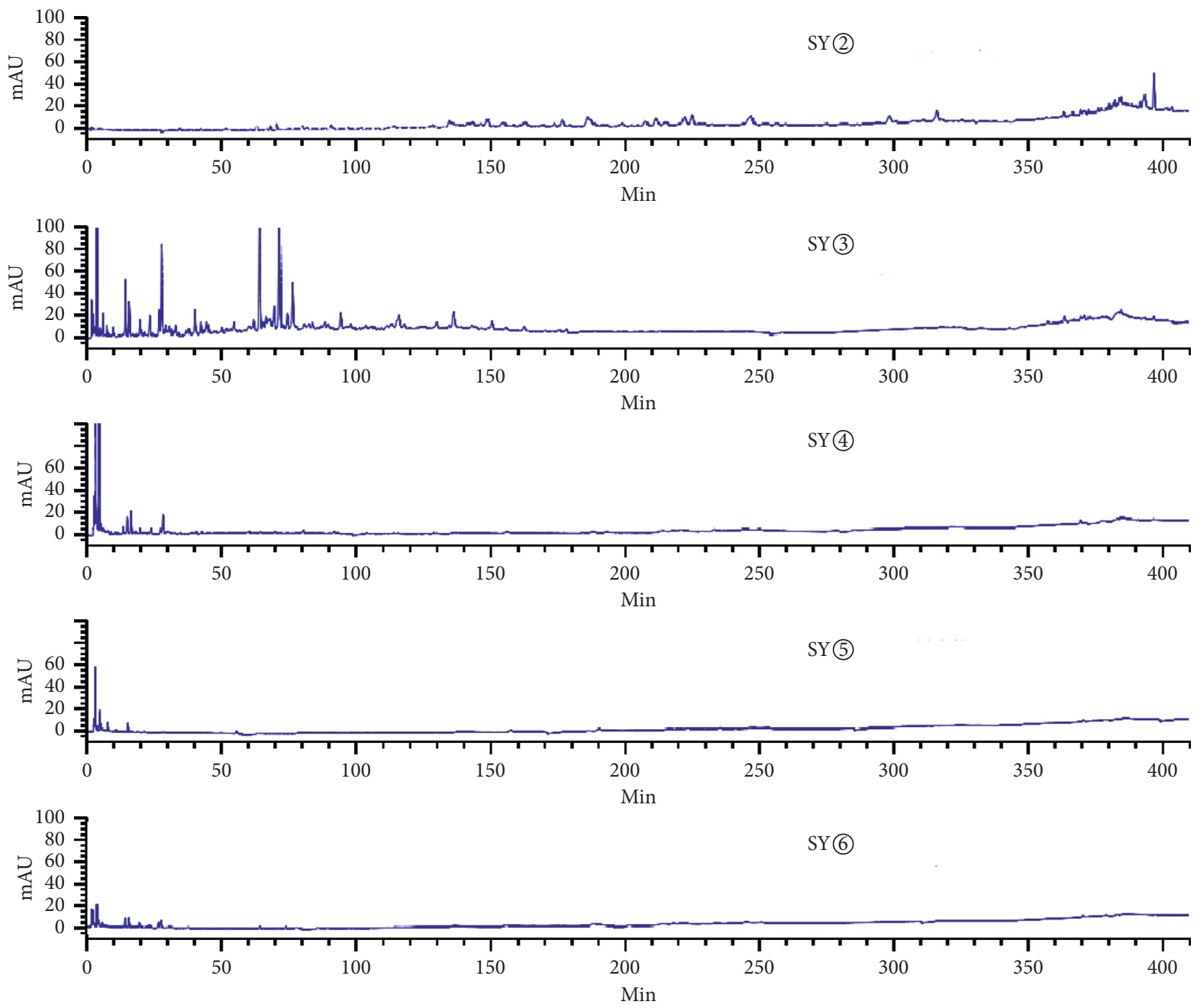

FIGURE 4: HPLC chromatogram for water extract (SY@6), hydromethanolic extract (SY(5), n-butanol extract (SY(4)), ethyl acetate extract (SY(3), and petroleum ether extract (SY(2) prepared from the stems and leaves of C. sappan. 

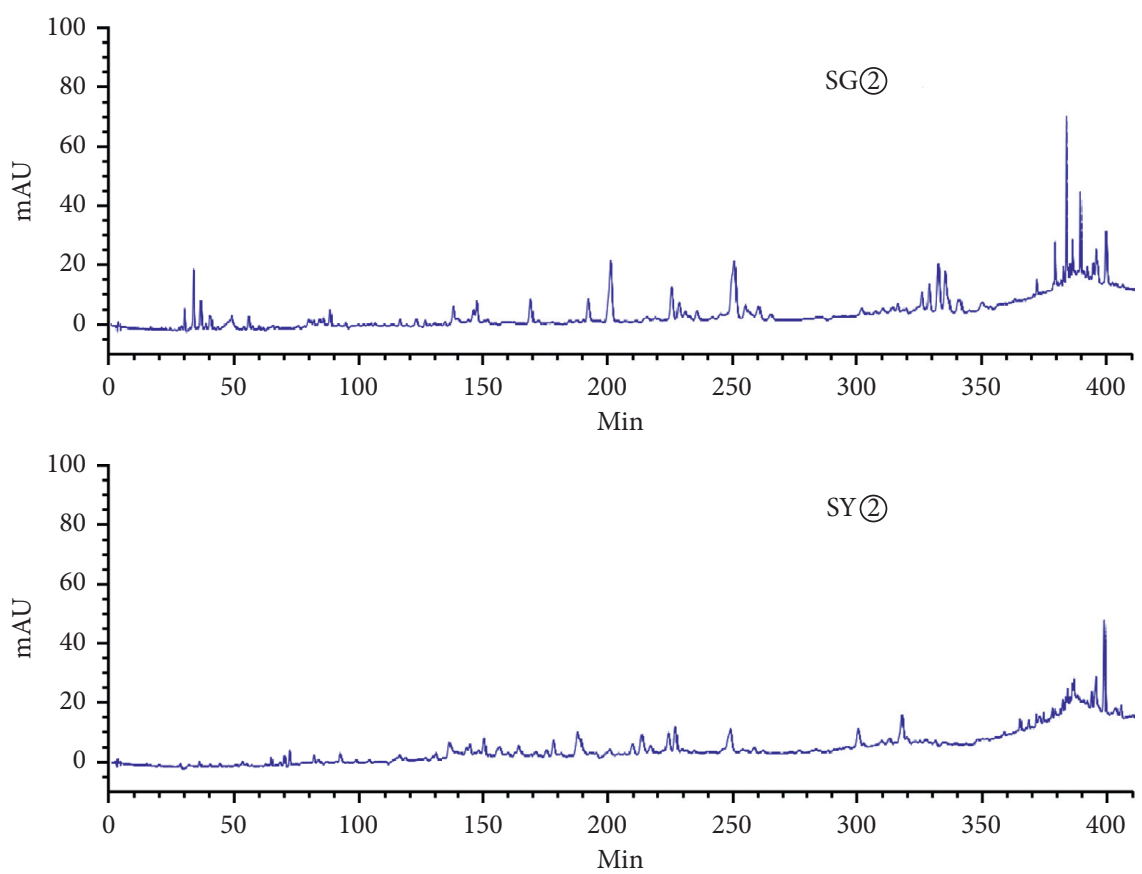

FIGURE 5: A comparison of the petroleum ether extracts (SG(2) and SY(2)).
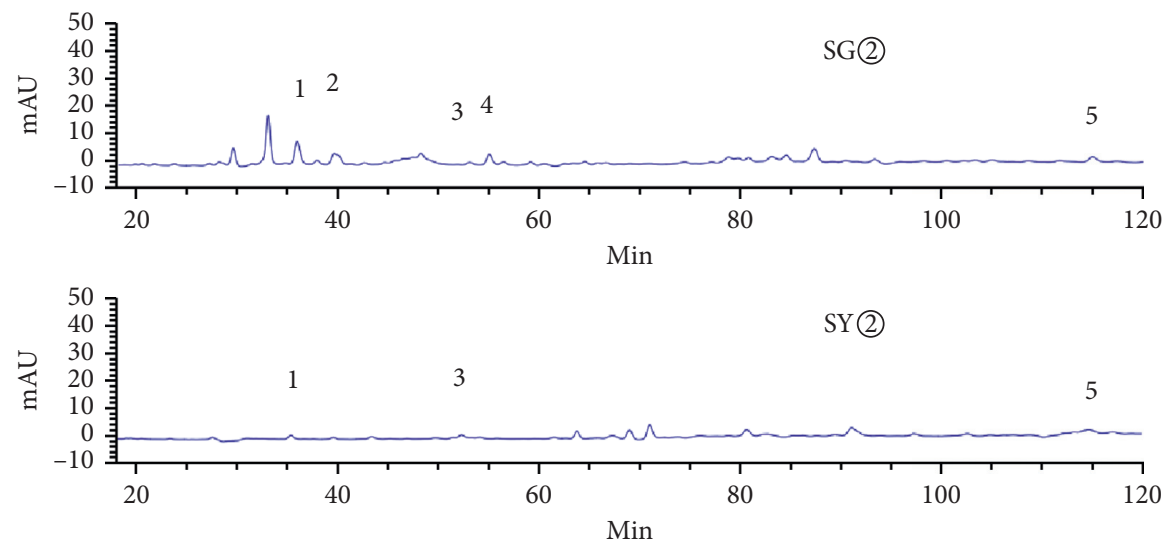

FIgURE 6: Common peaks identified by HPLC for SG(2) and SY(2) (1-5).
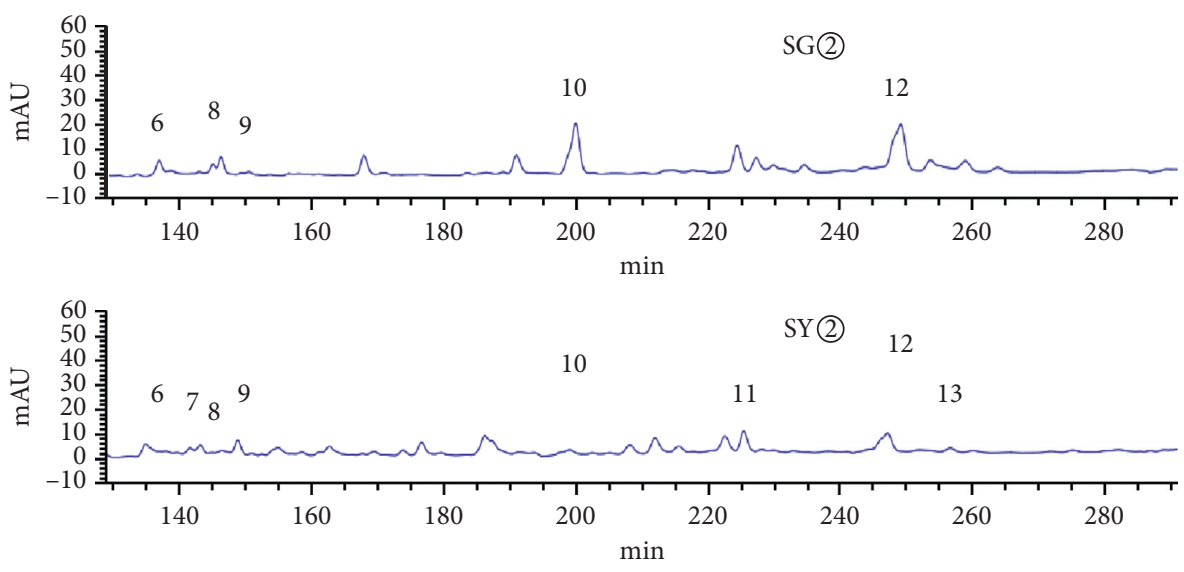

FIGURE 7: Common peaks identified by HPLC for SG(2) and SY(2) (6-13). 

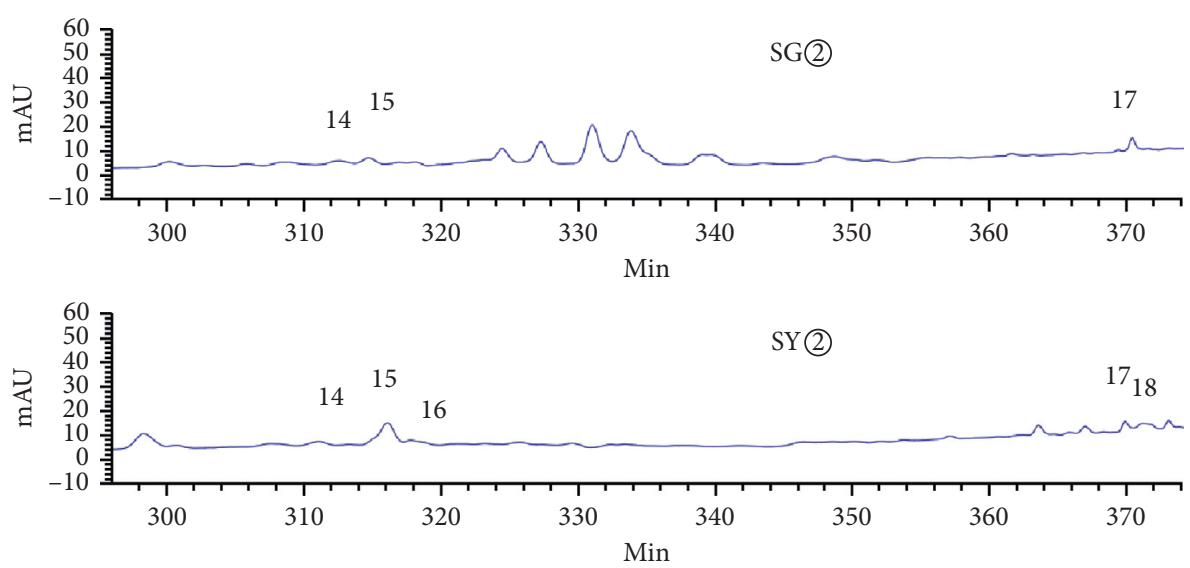

FIGURE 8: Common peaks identified by HPLC for SG(2) and SY(2) (14-16).
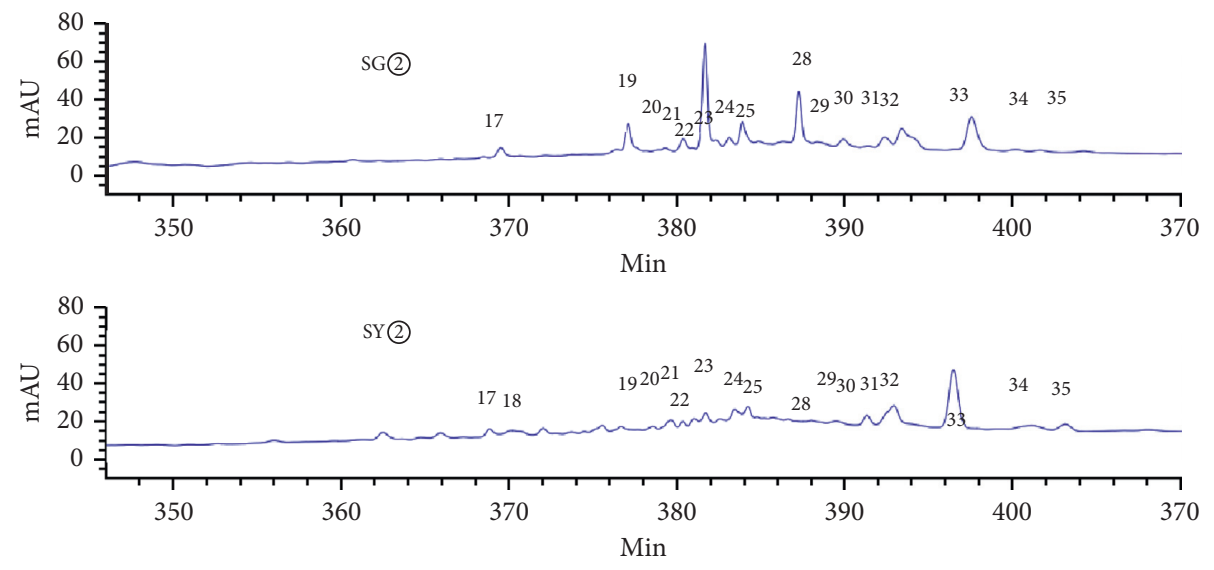

FIgURE 9: Common peaks identified by HPLC for SG(2) and SY(2) (17-35).

TABLE 3: Correlation between common antitumor activity and peaks of activity.

\begin{tabular}{lc}
\hline Peak & Correlation \\
\hline 1 & 0.355 \\
3 & 0.889 \\
5 & 0.736 \\
6 & 0.670 \\
8 & 0.407 \\
9 & 0.588 \\
10 & 0.354 \\
14 & 0.565 \\
15 & 0.629 \\
17 & 0.465 \\
19 & 0.499 \\
20 & 0.564 \\
22 & 0.484 \\
23 & 0.477 \\
24 & 0.441 \\
25 & 0.507 \\
26 & 0.622 \\
27 & 0.399 \\
28 & 0.626 \\
29 & 0.699 \\
30 & 0.667 \\
32 & 1.000 \\
33 & 0.593 \\
34 & 0.831 \\
35 & 0.489 \\
\hline
\end{tabular}


TABLE 4: Tumor weight and $\mathrm{IR}_{2}(n=10$, mean $\pm \mathrm{SD})$.

\begin{tabular}{lcccc}
\hline Group & Administration routes & Dose $(\mathrm{mg} / \mathrm{kg})$ & Tumor weight $(\mathrm{g})$ & $\mathrm{IR}_{2}(\%)$ \\
\hline Control group & i.p. + i.g. & - & 83 & $1.607 \pm 0.6241$ \\
\hline FU group & i.p. & 65 & $0.352 \pm 0.1862^{* * *}$ & - \\
\hline \multirow{2}{*}{ i.p. group } & i.p. & 20 & $0.624 \pm 0.4143^{* *}$ & 78.09 \\
\hline \multirow{2}{*}{ i.g. group } & \multirow{2}{*}{ i.g. } & 325 & $1.000 \pm 0.6528$ & 31.16 \\
& & 100 & $0.707 \pm 0.6373^{* *}$ & 37.77 \\
\hline
\end{tabular}

Note: compared with the control group, ${ }^{*} P<0.05,{ }^{* *} P<0.01$, and ${ }^{* * *} P<0.001$.

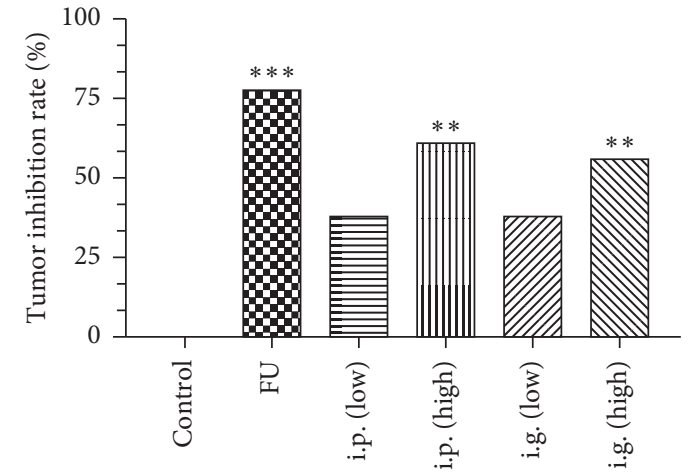

(a)

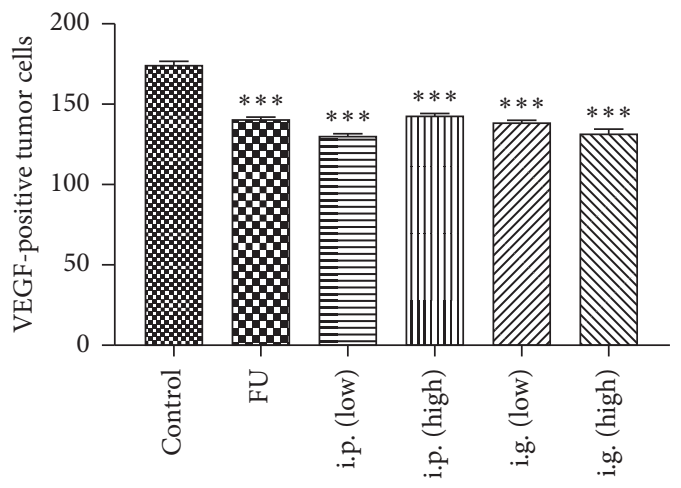

(c)

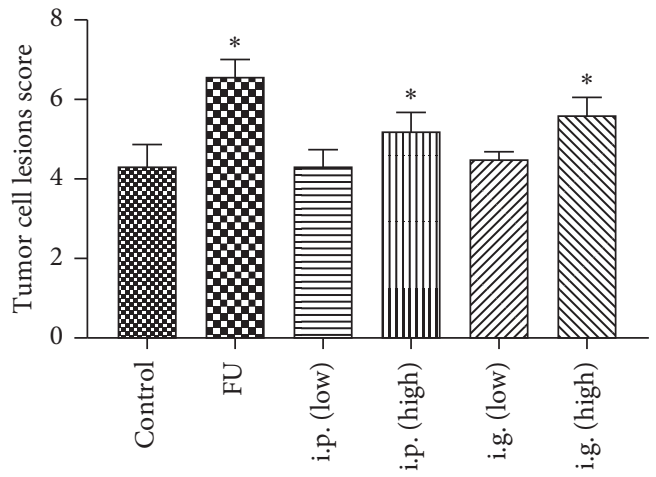

(b)

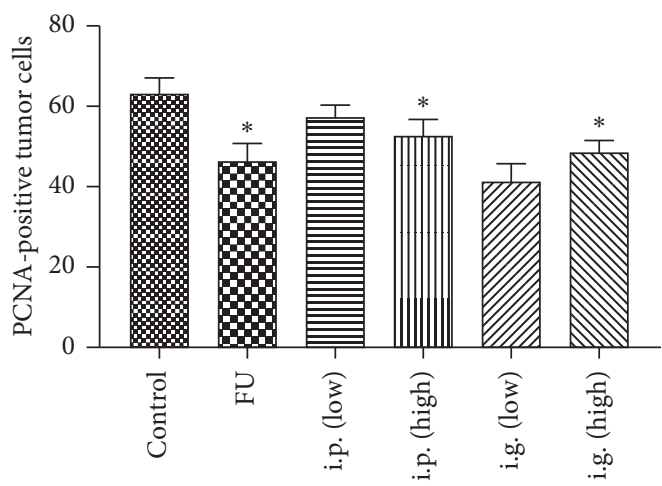

(d)

Figure 10: SY(2) antitumor effects in H22 hepatoma-bearing mice. All mice were administered for with SY(2) 12 days by the intragastric route $(100$ and $325 \mathrm{mg} / \mathrm{kg}$ ), by intraperitoneal injection $(20$ and $65 \mathrm{mg} / \mathrm{kg})$, and FU $(83 \mathrm{mg} / \mathrm{kg})$. (a) Tumor inhibition rate obtained by evaluating the weight of tumors, ${ }^{* *} P<0.01$ and ${ }^{* * *} P<0.001$ versus the control group. (b) Pathological scores for tumors (HE staining), ${ }^{*} P<0.05$ versus the control group. (c) VEGF expression, ${ }^{* * *} P<0.001$ versus the control group. (d) PCNA expression, ${ }^{*} P<0.05$ versus the control group.

Excessive proliferation and distant metastasis are important biological characteristics of malignant tumors. Therefore, developing methods to inhibit the proliferation of tumor cells and prevent their distant metastasis has become the main focus of clinical treatment. PCNA, VEGF, and other factors play important roles in promoting tumor proliferation and metastasis, PCNA is a cyclin, an accessory protein for cell DNA polymerase that exists in each developmental stage of tumor cells and the normal proliferation cycle of cells. However, PCNA is expressed at low levels in the G0 and G1 phases. The expression of PCNA begins in the G1 phase and reaches a peak in the $S$ phase but decreases significantly in the $M$ and G2 phases. This means that the changes in PCNA expression are consistent with DNA synthesis and are one of the most effective markers for detecting cell proliferation. PCNA expression can directly reflect the proliferation of tumor cells. The higher the expression of PCNA, the more active the state of cell proliferation; therefore, PCNA is regarded as being a useful indicator of the proliferation status of a cell [19-21]. Many studies have shown that the metastasis and growth of tumor tissue are dependent on a sufficient nutrient supply, new blood vessels, and oxygen. On the other hand, due to the high permeability of new blood vessels, tumor cells can readily pass through and spread. Revascularization provides 

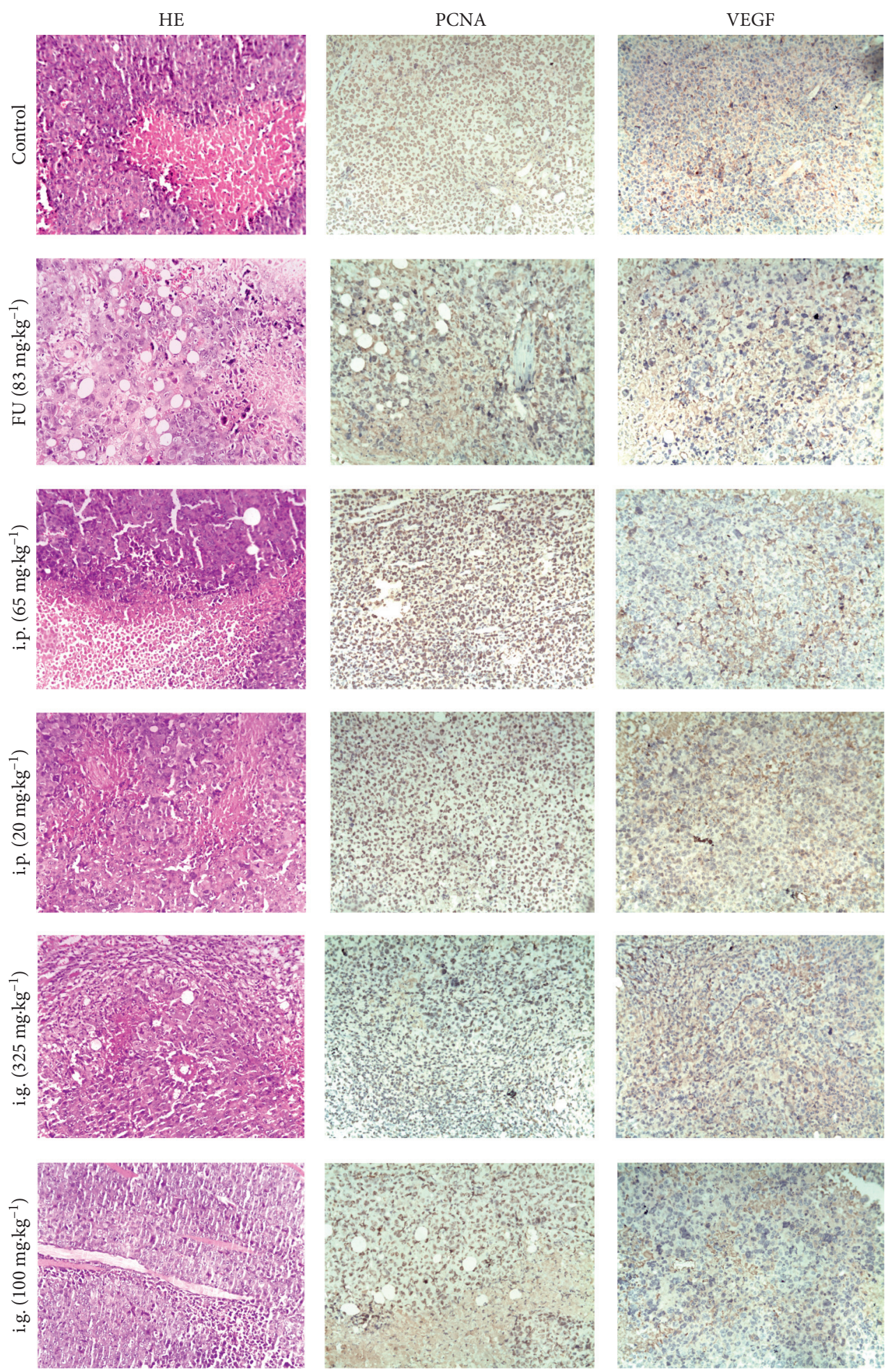

FIGURE 11: The antitumor effects of SY(2) in H22 hepatoma-bearing mice. All mice were administered with SY(2) for 12 days by the intragastric route $(100$ and $325 \mathrm{mg} / \mathrm{kg}$ ), intraperitoneal injection $(20$ and $65 \mathrm{mg} / \mathrm{kg}$ ), and by FU (83 mg/kg). Light microscopy 200x, bars $=100 \mu \mathrm{m}$, for VEGF, PCNA, and HE staining.

conditions for infiltration and metastasis [22]. The VEGF family are members of the receptor tyrosine kinase (RTK) family and play a key role in tumor angiogenesis. Consequently, VEGF is one of the most important inducers of angiogenesis and increases vascular permeability. Once
VEGF binds to its corresponding receptor, it stimulates the proliferation of vascular endothelial cells in the tumor and increases vascular permeability to provide a suitable basis for tumor infiltration and metastasis; consequently, VEGF is one of the main targets for tumor therapy [23]. 
TABLE 5: Pathological changes in tumor tissue and the expression of VEGF and PCNA factors $(n=10$, mean \pm SD).

\begin{tabular}{lcccc}
\hline Group & Dose $(\mathrm{mg} / \mathrm{kg})$ & Scores $^{\mathrm{a}}$ & VEGF $^{\mathrm{b}}$ & PCNA $^{\mathrm{c}}$ \\
\hline Control group & - & $4.31 \pm 0.54$ & $174.915 \pm 1.7091$ & $63.13 \pm 3.78$ \\
\hline FU group & 83 & $6.57 \pm 0.43^{*}$ & $141.21 \pm 0.9003^{* * *}$ & $46.12 \pm 4.45^{*}$ \\
\hline \multirow{2}{*}{ i.p. group } & 65 & $5.20 \pm 0.46^{*}$ & $144.189 \pm 1.0205^{* * *}$ & $52.80 \pm 3.90^{*}$ \\
\hline \multirow{2}{*}{ i.g. group } & 20 & $4.30 \pm 0.42$ & $131.066 \pm 0.9191^{* * *}$ & $57.40 \pm 2.82$ \\
\hline
\end{tabular}

${ }^{\mathrm{a}}$ Tumor cell lesion score (HE staining). ${ }^{\mathrm{b}}$ VEGF-positive tumor cells. ${ }^{\mathrm{c}} \mathrm{PCNA}$-positive tumor cells. Compared with the control group, ${ }^{*} P<0.05$ and ${ }^{* * *} P<0.001$.

We showed that the petroleum ether extract of leaves and stems could significantly inhibit the proliferation of tumor cells in vivo. Our data also demonstrated that, within the treatment groups, each dose inhibited the proliferation of tumors and that there was a significant reduction of tumor size compared to the model group; there was also a reduction in the extent of pathological changes. Immunohistochemical staining showed that the number of PCNA-positive cells within the tumor tissue was lower than in the model group, thus indicating that the mechanism underlying the inhibitory effect of SBLPE on tumor proliferation may be related to the inhibition of high PCNA expression. SBLPE was shown to inhibit the expression of VEGF in tumor tissues in an effective manner and that VEGF was the strongest angiogenesis-promoting factor and played a significant role in promoting the proliferation and metastasis of tumor tissues. Our data showed that SBLPE inhibited the expression of VEGF in vascular endothelial cells. Furthermore, our data indicated that SBLPE inhibited the growth and angiogenesis of H22 tumors in mice and helped to inhibit the distant metastasis of tumor cells through immature blood vessels. Combined with the expression of VEGF in SBLPE-treated tumor tissues, our data indicated that SBLPE may inhibit the growth and angiogenesis of H22 tumors by inhibiting the secretion of VEGF by tumor cells, therefore inhibiting the metastasis and proliferation of tumor cells.

The mechanisms underlying tumor cell proliferation and metastasis are complicated. Our research only investigated the mechanisms underlying anti-H22 tumor effects by evaluating antitumor growth and the growth of microvessels. Further studies are now needed to confirm these mechanisms and identify associated pathways. However, it is important to note that SBLPE is still a mixture. Further studies are now needed to identify the effective ingredients in SBLPE. However, our results provide a meaningful basis for the further identification of effective substances with antitumor effects.

\section{Conclusions}

In this paper, we demonstrated, for the first time, that petroleum ether extracts prepared from the leaves and stems of C. sappan can inhibit the proliferation of tumor cells. Compared with the resources that are traditionally used to prepare medical extracts (the roots and the trunk), the use of the stems and leaves would cause less damage to valuable resources. Therefore, our data indicates that the range of resources used to prepare extracts could be expanded to the leaves and stems, thus protecting valuable $C$. sappan resources.

Petroleum ether extracts prepared from the leaves and stems of $C$. sappan reduced the expression of PCNA and VEGF in the tumors of H22 hepatoma-bearing mice. Grey relational analysis indicated that the 11 common peaks of active fractions were closely related to antitumor activity. Our data provide a useful foundation for the extraction, isolation, and identification of compounds with antitumor activity.

\section{Data Availability}

All data for this project are available from the corresponding author.

\section{Disclosure}

Yuan Li and Minghong Dong are the co-first authors.

\section{Conflicts of Interest}

The authors declare that they have no conflicts of interest.

\section{Acknowledgments}

This work was supported by Guizhou Province Department of Science and Technology Guizhou University of Traditional Chinese Medicine Joint Fund Project (QianKeHe ZY ZI [2010]LKZ7021), Guizhou Province First-Class Discipline Construction Project (GNYL [2017] 008), Syndrome Pharmacology in Chinese Medicine (QianJiaoHe KY ZI [2017] 006), Guizhou Province Key Laboratory of Prescription.Guizhou Province International Science and Technology Cooperation Project (QianKeWaiHe G Zi [2010]7012), Guizhou Province Science and Technology Plan Project Tasks (QianKeHe SY Zi [2009]3104), Guizhou University of Traditional Chinese Medicine Ph.D. Initiated Project (GuiZhongYiBoShiQiDong[2020]75Hao).

\section{References}

[1] X. Ren, P. Hu, L. Kong, and W. Wang, "Research progress on chemical constituents of sappanwood," Fine and Specialty Chemicals, vol. 27, no. 5, pp. 34-37, 2019.

[2] H. Zhang, Z. Zhang, X. Huang, H. Li, Y. Sun, and X. Huang, "Effects of sappan decoction on blood sugar, renal function 
and renal pathology in rats with diabetic nephropathy," Lishizhen Medicine and Materia Medica Research, vol. 22, no. 5, pp. 1255-1256, 2011.

[3] P. Jin, Y. Zhou, Q. Song, X. Zhen, and X. Li, "Experimental study on the immunosuppressive effect of the effective ingredients of sappan," Journal of Chinese Medicinal Materials, vol. 30, no. 2, pp. 196-200, 2007.

[4] Q. Zhang, J. L. Liu, X. M. Qi et al., "Inhibitory activities of Lignum Sappan extractives on growth and growth-related signaling of tumor cells," Chinese Journal of Natural Medicines, vol. 12, no. 8, p. 607, 2014.

[5] X. H. Yang, L. S. Reng, L. L. Zhao et al., "Study on inhibitory effect of prohematoxylin B on tumor cells BTT T24 HeLa and SW480," Chinese Remedies \& Clinics, vol. 15, no. 8, p. 83, 2015.

[6] T. Zhang, X. Fan, L. Song et al., "c-Fos is involved in inhibition of human bladder carcinoma T24 cells by brazilin," IUBMB Life, vol. 67, no. 3, p. 175, 2015.

[7] C. H. Liang, L. P. Chou, T. H. Chou et al., "Brazilein from Caesalpinia sappan L. antioxidant inhibits adipocyte differentiation and induces apoptosis through caspase-3 activity and anthelmintic activities against hymenolepis nana and anisakis simplex," Evid Based Complement Alternat Med, vol. 2013, Article ID 864892, 14 pages, 2013.

[8] D. Y. Lee, M. K. Lee, G. S. Kim et al., "Brazilin inhibits growth and induces apoptosis in human glioblastoma cells," Molecules, vol. 18, no. 2, p. 2449, 2013.

[9] X. H. Yang, L. S. Ren, S. G. Zhang et al., "Antitumor effects of purified protosappanin B extracted from Lignum Sappan," Integrative Cancer Therapies, vol. 15, no. 1, pp. 87-95, 2016.

[10] S. H. Kim, H. N. Lyu, Y. S. Kim et al., "Brazilin isolate from Caesalpinia sappan suppresses nuclear envelope reassembly by inhibiting barrier-to-autointegration factor phosphorylation," Journal of Pharmacology and Experimental Therapeutics, vol. 352, no. 1, pp. 175-184, 2015.

[11] Y. B. Bai, C. Li, Y. M. Zhou et al., "Chemical constituents of triterpenoids from Prunella vulgaris and their antitumor activities," Chinese Traditional and Herbal Drugs, vol. 46, no. 24, pp. 3623-3629, 2015.

[12] L. Duan, Y. P. Zhang, Y. P. Miao, and J. Fu, "In vivo and in vitro effects of Miao medicine Indigofera stachyoides extracts on breast cancer 4T1 cells," Chinese Traditional and Herbal Drugs, vol. 49, no. 12, pp. 2902-2907, 2018.

[13] L. Fan, Y. P. Wu, and H. Qu, "Selaginella Pulvinata extract exerts antitumor efficacy in $\mathrm{H} 22$ tumor-bearing mice via induction of apoptosis," Journal of Nanjing University of Traditional Chinese Medicine, vol. 35, no. 6, pp. 664-670, 2019.

[14] Y. Tsuji, M. Kuramochi, T. Izawa et al., "Hepatic myoepithelial carcinoma in a dog: immunohistochemical comparison with other canine hepatic carcinomas," Veterinary Pathology, vol. 56, no. 2, pp. 889-894, 2019.

[15] J. Q. Liang, J. Wang, W. N. Xiong, H. X. Huang, E. W. Hao, and Z. P. Wang, "Spectrum-effect relationship of leaf extracts from mangifera indica based on grey relational analysis," China Journal of Experimental Traditional Medical Formulae, vol. 21, no. 1, pp. 121-125, 2015.

[16] Y. Wang, X. Peng, Y. L. He et al., "Spectrum-effect relationship of anti-inflammatory active components from nonvolatile fraction of blumea balsamifera based on gray correlation analysis," China Journal of Experimental Traditional Medical Formulae, vol. 25, no. 4, pp. 180-186, 2019.

[17] G. Shen, D. S. Jing, F. Yang, J. Chen, R. Ge, and G. E. Yang, "Correlation analysis between HPLC fingerprint and antiinflammatory activity of Speranskiae Tuberculatae Herba,"
China Journal of Experimental Traditional Medical Formulae, vol. 25, no. 12, pp. 174-180, 2019.

[18] C. Shao-Qing, W. Xuan, S. Ming-Ying et al., "“Efficacy theory” may help to explain characteristic advantages of traditional Chinese medicines," China Journal of Chinese Materia Medica, vol. 40, no. 17, p. 3435, 2015.

[19] S. S. Essawy, S. E. Bilasy, H. M. F. Mohammad, and A. A. M. Shaalan, "Effect of celecoxib and cisplatin combination on apoptosis and cell proliferation in a mouse model of chemically-induced colonic aberrant crypt foci," Egyptian Journal of Basic and Applied Sciences, vol. 4, no. 4, pp. 323331, 2017.

[20] M. I. Carvalho, I. Pires, J. Prada, L. Lobo, and F. L. Queiroga, "Ki-67 and PCNA expression in canine mammary tumors and adjacent nonneoplastic mammary glands," Veterinary $\mathrm{Pa}$ thology, vol. 53, no. 6, pp. 1138-1146, 2016.

[21] S. Li, B. Luo, and J. Luo, "The expression of serum PSA in patients with prostate cancer and its correlation with the expression of PCNA," Chinese Journal of Human Sexuality, vol. 27, no. 8, pp. 14-18, 2018.

[22] H. Fang and L. Chen, "Effect of curcumin combined with endostatin on sarcoma growth inhibition and angiogenesis in mice," Chinese Journal of Modern Applied Pharmacy, vol. 37, no. 5, pp. 572-576, 2018.

[23] T. Isayeva, S. Kumar, and S. Ponnazhagan, "Anti-angiogenic gene therapy for cancer," Oncology Letters, vol. 16, no. 1, pp. 687-702, 2004. 